\title{
Novel method for fast trabectedin quantification using hydrophilic interaction liquid chromatography and tandem mass spectrometry for human pharmacokinetic studies
}

\author{
Emanuela Di Gregorio $^{\mathrm{a}, \mathrm{b}}$, Gianmaria Miolo ${ }^{\mathrm{c}}$, Agostino Steffan ${ }^{\mathrm{a}}$, Giuseppe Corona ${ }^{\mathrm{a}, *}$ \\ a Immunopathology and Cancer Biomarkers Unit, IRCCS CRO Centro di Riferimento Oncologico Aviano, 33081, Aviano (PN), Italy \\ ${ }^{\mathrm{b}}$ Department of Molecular Sciences and Nanosystems, University of Venice, 30170, Mestre (VE), Italy \\ c Medical Oncology and Cancer Prevention Unit, IRCCS CRO Centro di Riferimento Oncologico Aviano, 33081, Aviano (PN), Italy
}

\section{A R T I C L E I N F O}

\section{Article history:}

Received 2 January 2020

Received in revised form 12 March 2020

Accepted 14 March 2020

Available online 17 March 2020

\section{Keywords:}

Trabectedin

HILIC

LC-MS/MS

Cancer

Pharmacokinetics

\begin{abstract}
A B S T R A C T
Few time-consuming bioanalytical methods are currently available for trabectedin quantification in clinical investigations. Here we present a novel, fast and sensitive method for trabectedin determination in human plasma based on hydrophilic interaction liquid chromatography and tandem mass spectrometry (HILIC-MS/MS). Plasma samples are treated with acetonitrile- $0.1 \%$ formic acid and the solvent extract is directly injected into an Acquity BEH Amide column $(2.1 \times 100 \mathrm{~mm}, 1.7 \mu \mathrm{m})$ operating in HILIC mode at $0.2 \mathrm{~mL} / \mathrm{min}$ with $80: 20$ acetonitrile- $0.1 \%$ formic acid in water. The analyte is separated by an organic solvent gradient and quantified by an Agilent Ultivo triple quadrupole mass spectrometer operating in multiple reaction monitoring (MRM) mode. The quantitative MRM transitions were $\mathrm{m} / \mathrm{z} 762 \rightarrow 234$ and $m / z 765 \rightarrow 234$ for trabectedin and its $d_{3}$-labeled derivative, respectively. The lower limit of quantification (LLOQ) was $0.01 \mathrm{ng} / \mathrm{mL}$ and the assay was linear up to $2.5 \mathrm{ng} / \mathrm{mL}$. The intra- and inter-day relative error ranged from $1.19 \%$ to $8.52 \%$, while the relative standard deviation was less than $12.35 \%$. The method was used to determine the pharmacokinetic profiles of trabectedin in 26 patients with soft tissue sarcoma, showing that this new HILIC-MS/MS method is suitable for use in clinical research.
\end{abstract}

(C) 2020 Elsevier B.V. All rights reserved.

\section{Introduction}

Trabectedin is a natural anticancer drug first isolated from the marine tunicate Ecteinascidia turbinate and nowadays synthetically produced (ATC code: L01CX01). It exerts its antitumoral activity by alkylating guanines in the minor groove of DNA [1] and, conversely from other DNA alkylating agents, it induces a cascade of events that interfere with the function of several transcription factors, DNA binding proteins, and DNA repair pathways, leading to cancer cell death $[1,2]$. In addition to this toxic mechanism, trabectedin blocks the production of growth factors and cytokines by both normal and tumor cells, suggesting that its antitumor activity also involves tumor microenvironment modifications [3].

Trabectedin is indicated for the treatment of advanced soft tissue sarcoma (STS) and platinum-sensitive recurrent ovarian cancer [4]. It is currently being tested, alone or in combination, in clinical

\footnotetext{
* Corresponding author at: Immunopathology and Cancer Biomarkers Unit, Translational Research Department, IRCCS CRO Centro di Riferimento Oncologico Aviano, 33081, Aviano (PN), Italy.

E-mail address: giuseppe.corona@cro.it (G. Corona).
}

trials for these and other malignancies [5-8]. Dosage of trabectedin is critical for the development of phase I and II studies where drug concentrations in plasma are normally very low. Thus, to investigate the clinical pharmacokinetic and pharmacodynamic properties of this drug in different clinical settings, highly sensitive bioanalytical methods are needed.

Currently, a few methods for trabectedin determination involving liquid chromatography-tandem mass spectrometry (LCMS/MS) are available. However, these methods generally require large sample volumes and involve time-consuming pre-analytical steps. The first LC-MS/MS method for trabectedin quantification, which had a lower limit of quantification (LLOQ) of $0.01 \mathrm{ng} / \mathrm{mL}$, required a complex plasma solid-phase extraction (SPE) process and $500 \mu \mathrm{L}$ of sample [9]. Successively, an online column-switching extraction step, coupled with tandem MS, was introduced to automatize the pre-analytical purification and concentration steps [10]. This online-SPE LC-MS/MS method needed only $100 \mu \mathrm{L}$ of sample but had a LLOQ of $0.05 \mathrm{ng} / \mathrm{mL}$ [10]. Nonetheless, the use of this bioanalytical approach was limited by the need for an unconventional LC instrumental configuration. Recently, an LC-MS/MS method with an improved LLOQ of $0.025 \mathrm{ng} / \mathrm{mL}$ was described and 
(a)

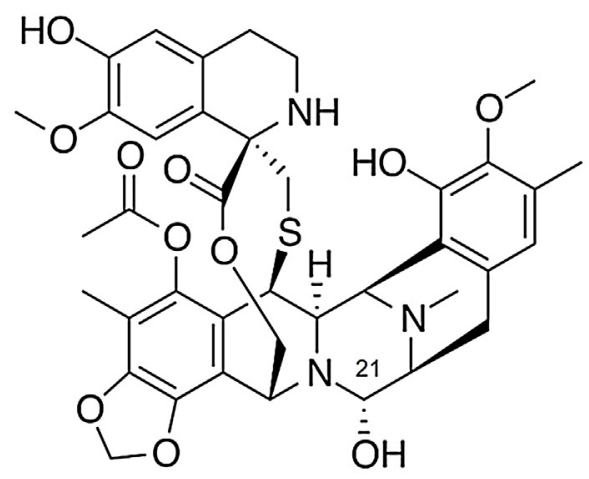

$$
\mathrm{C}_{39} \mathrm{H}_{43} \mathrm{~N}_{3} \mathrm{O}_{11} \mathrm{~S}
$$

Exact Mass: 761.26183 (b)

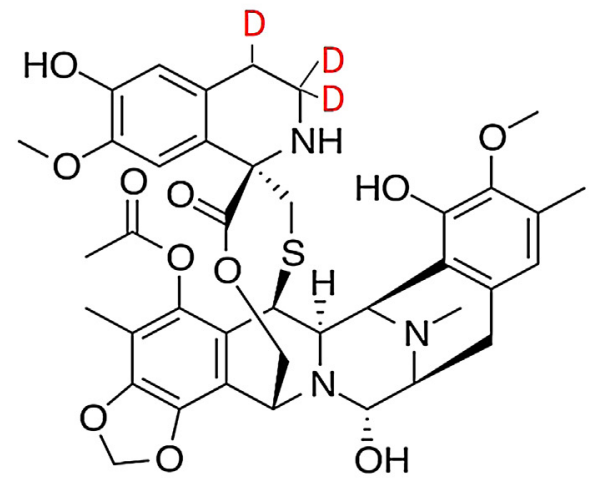

Exact Mass: 764.26183

Fig. 1. Chemical structures of trabectedin (a) and $d_{3}$-trabectedin (b).

tested pharmacokinetically in one patient under treatment [11]. Despite the low LLOQ this method involves an extended sample pre-treatment process consisting of extraction and solvent drying steps.

Here we describe a simpler, more direct analytical method for trabectedin quantification in human plasma. To overcome the drawbacks of existing methods, our new method combines a simple sample preparation process with hydrophilic interaction liquid chromatography and tandem mass spectrometry (HILIC-MS/MS). This analytical integration results in good sensitivity for trabectedin determination in patient-derived plasma, making it suitable for high-throughput human clinical pharmacokinetic investigations.

\section{Materials and methods}

\subsection{Chemicals and plasma samples}

Acetonitrile (LC-MS grade) was purchased from Carlo Erba Reagents (Milan, Italy) and further purified by distillation. Formic acid and dimethyl sulfoxide (DMSO) were obtained from SigmaAldrich. Ultrapure water was generated by a Milli-Q Plus system (Millipore, Billerica, MA, USA).

Analytical reference standards of trabectedin $\left(\mathrm{C}_{39} \mathrm{H}_{43} \mathrm{~N}_{3} \mathrm{O}_{11} \mathrm{~S}\right.$, MW $761.837 \mathrm{~g} / \mathrm{mol}$, Fig. 1a) and its deuterium-labeled derivative $\mathrm{d}_{3}$-trabectedin $\left(\mathrm{C}_{39} \mathrm{H}_{40} \mathrm{D}_{3} \mathrm{~N}_{3} \mathrm{O}_{11} \mathrm{~S}\right.$, MW $764.837 \mathrm{~g} / \mathrm{mol}$, Fig. $1 \mathrm{~b}$ ), used as an internal standard, were provided by PharmaMar (Colmenar Viejo, Madrid, Spain). Drug-free human plasma, used to prepare daily standard calibration curves and quality control (QC) samples, was from healthy blood donors at CRO Aviano.

Clinical plasma samples were obtained from STS patients who were receiving trabectedin at a dose of $1.5 \mathrm{mg} / \mathrm{m}^{2}$ by continuous 24 -h intravenous infusion. Whole blood was collected before the start of infusion and after $2,8,24,24.5,25,28,32$, and $48 \mathrm{~h}$, in tubes containing EDTA as anticoagulant. Samples were centrifuged at $4{ }^{\circ} \mathrm{C}$ for $10 \mathrm{~min}$ at $1900 \mathrm{~g}$ (Thermo Scientific Heraeus Megafuge 16R centrifuge). The plasma was transferred to polypropylene Eppendorf tubes and stored at $-30^{\circ} \mathrm{C}$ until analysis. The study protocol was approved by the CRO Institutional Ethical Committee (no. 2015.004CE, 09/03/2015), and all patients gave written informed consent.

\subsection{Preparation of standard and QC solutions}

Two stock solutions each of trabectedin and $\mathrm{d}_{3}$-trabectedin at $100 \mu \mathrm{g} / \mathrm{mL}$ in DMSO were prepared. The trabectedin stock solutions were diluted into two series of working solutions at the nominal concentrations of 100,10 and $1 \mathrm{ng} / \mathrm{mL}$ in acetonitrile-0.1 $\%$ formic acid in water $(70: 30, v / v)$. These solutions were used to prepare plasma calibrators and QC samples. A $d_{3}$-trabectedin working solution (internal standard) was prepared at $100 \mathrm{ng} / \mathrm{mL}$ in acetonitrile-0.1\% formic acid in water $(70: 30, v / v)$ and stored at $-30^{\circ} \mathrm{C}$.

Eight-point calibration curves were set up for each batch of analysis and during the validation study. Plasma calibrators were obtained by diluting working solutions of trabectedin in drug-free plasma at final concentrations of (A) $2.5 \mathrm{ng} / \mathrm{mL}$, (B) $1.0 \mathrm{ng} / \mathrm{mL}$, (C) $0.5 \mathrm{ng} / \mathrm{mL}$, (D) $0.25 \mathrm{ng} / \mathrm{mL}$, (E) $0.1 \mathrm{ng} / \mathrm{mL}$, (F) $0.05 \mathrm{ng} / \mathrm{mL}$, (G) $0.025 \mathrm{ng} / \mathrm{mL}$, and $(\mathrm{H}) 0.01 \mathrm{ng} / \mathrm{mL}$. Three QC samples, at high $(0.80 \mathrm{ng} / \mathrm{mL}, \mathrm{QC}-\mathrm{H})$, medium $(0.16 \mathrm{ng} / \mathrm{mL}, \mathrm{QC}-\mathrm{M})$ and low $(0.04 \mathrm{ng} / \mathrm{mL}, \mathrm{QC}-\mathrm{L})$ concentrations, were also prepared in drugfree plasma. Each batch of analysis included a double blank (plasma without the internal standard) and a blank (plasma with the internal standard).

\subsection{Pre-analytical sample processing}

After thawing, plasma, calibrators and QC samples ( $50 \mu \mathrm{L}$ each) were transferred to $1.5 \mathrm{~mL}$ Eppendorf polypropylene tubes for solvent extraction. Then, acetonitrile solution containing $1 \%$ formic acid and $0.1 \mathrm{ng} / \mathrm{mL} \mathrm{d}_{3}$-trabectedin $(200 \mu \mathrm{L})$ was added. The tubes were vigorously vortexed and centrifuged at $20,800 \mathrm{~g}$ for $10 \mathrm{~min}$ at $4{ }^{\circ} \mathrm{C}$ using a 5430R Eppendorf centrifuge. The supernatant was transferred to an auto-sampler glass vial, and $3 \mu \mathrm{L}$ was injected into the LC-MS/MS system.

\subsection{Liquid chromatography}

The ultra-performance liquid chromatography (UPLC) system consisted of a 1290 Infinity II binary pump with an integrated degassing unit equipped with a column thermostat and a 1290 auto-sampler (Agilent Technologies). Chromatography was run on 
Table 1

MRM transitions and optimized parameters for trabectedin and $\mathrm{d}_{3}$-trabectedin.

\begin{tabular}{lllll}
\hline & Precursor $(\mathrm{m} / \mathrm{z})$ & Product $(\mathrm{m} / \mathrm{z})$ & $\mathrm{CE}(\mathrm{V})$ & Fragmentor $(\mathrm{V})$ \\
\hline $\begin{array}{l}\text { Quantifier MRM } \\
\text { trabectedin }\end{array}$ & 762 & & & \\
$\mathrm{~d}_{3}$-trabectedin & 765 & 234 & 30 & 150 \\
Qualifier MRM & & 234 & 30 & 150 \\
trabectedin & 762 & & & \\
trabectedin & 762 & 206 & 30 & 150 \\
$\mathrm{~d}_{3}$-trabectedin & 765 & 557 & 25 & 150 \\
$\mathrm{~d}_{3}$-trabectedin & 765 & 206 & 30 & 150 \\
\hline
\end{tabular}

CE, collision energy; MRM, multiple reaction monitoring.

an Acquity BEH Amide $2.1 \times 100 \mathrm{~mm}, 1.7 \mu \mathrm{m}$ column (Waters, Milford, MA, USA) operating in HILIC mode. The column was kept at $25^{\circ} \mathrm{C}$ and equilibrated with $80 \%$ mobile phase B (acetonitrile- 0.1 $\%$ formic acid) and $20 \%$ mobile phase $A$ (water $-0.1 \%$ formic acid) delivered at a flow rate of $0.2 \mathrm{~mL} / \mathrm{min}$. The gradient started with an isocratic step at $80 \% \mathrm{~B}$ for $1.5 \mathrm{~min}$, then fell to $50 \% \mathrm{~B}$ at $5 \mathrm{~min}$ and was followed by an isocratic step of 1 min before returning to the initial condition of $80 \%$ B at $6.1 \mathrm{~min}$. An equilibration time of $3 \mathrm{~min}$ was allowed before the next sample was injected.

\subsection{Tandem mass spectrometry}

The UPLC system was coupled with an Ultivo triple quadrupole mass spectrometer (Agilent Technologies). Trabectedin was quantified using positive electrospray ionization (ESI) and multiple reaction monitoring (MRM) mode. The trabectedin MS parameters were optimized through the flow injection of the standard solutions at a concentration of $1.0 \mu \mathrm{g} / \mathrm{mL}$ in acetonitrile- $1 \%$ formic acid in water $(1: 1 \mathrm{v} / \mathrm{v})$. The quantifier MRM transitions were selected on the basis of the most intense fragment ion. They were $\mathrm{m} / \mathrm{z}$ $762 \rightarrow 234$ and $m / z 765 \rightarrow 234$ for trabectedin and $d_{3}$-trabectedin, respectively. Moreover, the MRM transitions used as qualifier were $m / z 762 \rightarrow 206$ and $m / z 762 \rightarrow 557$ for trabectedin, and $m / z 765 \rightarrow 206$ and $m / z 765 \rightarrow 560$ for $\mathrm{d}_{3}$-trabectedin (Table 1 ). The ESI Jet Stream source parameters were optimized to have the most intense MRM signals. They were: gas temperature, $350^{\circ} \mathrm{C}$; gas flow, $10 \mathrm{~L} / \mathrm{min}$; nebulizer gas, $30 \mathrm{psi}$; sheath gas temperature, $400^{\circ} \mathrm{C}$; sheath gas flow, $12 \mathrm{~L} / \mathrm{min}$; capillary voltage, $4000 \mathrm{~V}$; and nozzle voltage, $50 \mathrm{~V}$. Data were processed with Mass Hunter Quantitative Data Analysis software.

\subsection{Method validation}

The method was validated according to US Food and Drug Administration guidelines [12]. The examined parameters were linearity, LLOQ intra- and inter-day accuracy and precision, recovery, matrix effect, selectivity and stability.

Linearity was evaluated by plotting relative peak area ratio (analyte/internal standard) vs. the analyte concentration from three independent plasma calibration curves. Linear least-squares regression analysis and weighting factors were applied to determine slope, intercept and correlation coefficient $\left(R^{2}\right)$. The accuracy and precision of back-calculated concentrations of calibrators were expected to be $\leq 15 \%$. Accuracy was expressed as the relative error (RE), i.e. the percentage of deviation from the nominal value:

$$
\mathrm{RE}=\frac{\text { observed concentration }- \text { nominal concentration }}{\text { nominal concentration }} \times 100
$$

Precision was expressed as the relative standard deviation (RSD), calculated as:

$\mathrm{RSD}=\frac{\text { standard deviation }}{\text { mean }} \times 100$
LLOQ was assessed as the lowest plasma trabectedin concentration within the calibration curve with RE (accuracy) and RSD (precision) $\leq 20 \%$. Intra-day and inter-day accuracy and precision were determined by analyzing 6-12 replicates of each QC sample on three different days (days 1-3). Accuracy and precision were required to be $\leq 15 \%$ for all QC sample determinations.

Overall recovery of trabectedin was estimated by comparing in triplicate the peak area of the plasma QC samples with the signal obtained from neat solutions. Matrix effect was estimated by comparing in triplicate the peak responses of protein-free plasma extract spiked with trabectedin and $\mathrm{d}_{3}$-trabectedin with those of a neat solution, as described [13].

Selectivity was studied by investigating if the endogenous matrix compounds could interfere with the quantification of trabectedin and $\mathrm{d}_{3}$-trabectedin. Six different plasma samples were analyzed alone (double blank) or with trabectedin added at the LLOQ. Selectivity was defined by the absence of matrix peaks near the trabectedin retention time, allowing trabectedin quantification with RSD and $\mathrm{RE} \leq 20 \%$.

Stability experiments were performed in triplicate at each QC concentration. Short-term stability was evaluated after $4 \mathrm{~h}$ for samples maintained at $4{ }^{\circ} \mathrm{C}$ or at room temperature. Plasma extract stability was investigated in samples maintained at $4{ }^{\circ} \mathrm{C}$ in the autosampler injector for $24 \mathrm{~h}$. Freeze-thaw stability was assessed on samples frozen at $-30^{\circ} \mathrm{C}$ for $24 \mathrm{~h}$ for each cycle, thawed and then kept at room temperature for $1 \mathrm{~h}$. Long-term stability was assessed by analyzing samples after 3 months of storage at $-30^{\circ} \mathrm{C}$. Samples were considered stable when the difference in trabectedin concentration from the nominal value was less than $\pm 15 \%$.

\subsection{Clinical suitability}

The method was used to quantify trabectedin in plasma from 26 STS patients treated with $1.5 \mathrm{mg} / \mathrm{m}^{2}$ trabectedin administered as a $24 \mathrm{~h}$ continuous intravenous infusion. Pharmacokinetic parameters were calculated using a non-compartmental model, with $\mathrm{C}_{\max }$ value being directly obtained from the pharmacokinetic profile data. The area under the curve up to $48 \mathrm{~h}\left(\mathrm{AUC}_{0-48 \mathrm{~h}}\right)$ was calculated using the trapezoidal method, the area under the moment curve $\left(\mathrm{AUMC}_{0-48 \mathrm{~h}}\right.$ ) as (concentration • time) time data plot, and the mean resident time (MRT) as $\mathrm{AUC}_{0-48 \mathrm{~h}} / \mathrm{AUMC}_{0-48 \mathrm{~h}}$ ratio.

\section{Results and discussion}

\subsection{Mass spectrometry}

The ESI-positive scans of trabectedin and its $\mathrm{d}_{3}$-labeled derivative showed multiple peaks due to the presence of different ion species (Fig. 2). Under the solvent conditions used, the main peak corresponded to the protonated molecule ion $[\mathrm{M}+\mathrm{H}]^{+}$at $m / z 762$ and $m / z 765$ for trabectedin and $d_{3}$-trabectedin, respectively. The less intense signals at $m / z 744$ and $m / z 747$ derived from loss of water $\left[\mathrm{M}-\mathrm{H}_{2} \mathrm{O}+\mathrm{H}\right]^{+}$of the molecular species. These results differ from previous reports where such dehydrated molecular ion species were more abundant [9-11]. The lower secondary peaks at $\mathrm{m} / \mathrm{z} 784$ and $\mathrm{m} / \mathrm{z} 787$ for trabectedin and $\mathrm{d}_{3}$-trabectedin, respectively, are attributed to their sodium adducts $[\mathrm{M}+\mathrm{Na}]^{+}$(Fig. 2a,b). Moreover, when unpurified acetonitrile was used as solvent, the trabectedin spectrum displayed an unexpected peak at $\mathrm{m} / \mathrm{z} 771$, explained by the addition of cyanide to dehydrated trabectedin $\left[\mathrm{M}-\mathrm{H}_{2} \mathrm{O}+\mathrm{H}+27\right]^{+}$(see Electronic Supplementary Materials, Fig. S1). Analogously, when methanol was used, an ion at $m / z 776$ was observed due to the formation of a methoxy derivative or a methanol cluster, as previously suggested [9]. Formation of the cyanide and methoxy derivatives could be explained by the high 

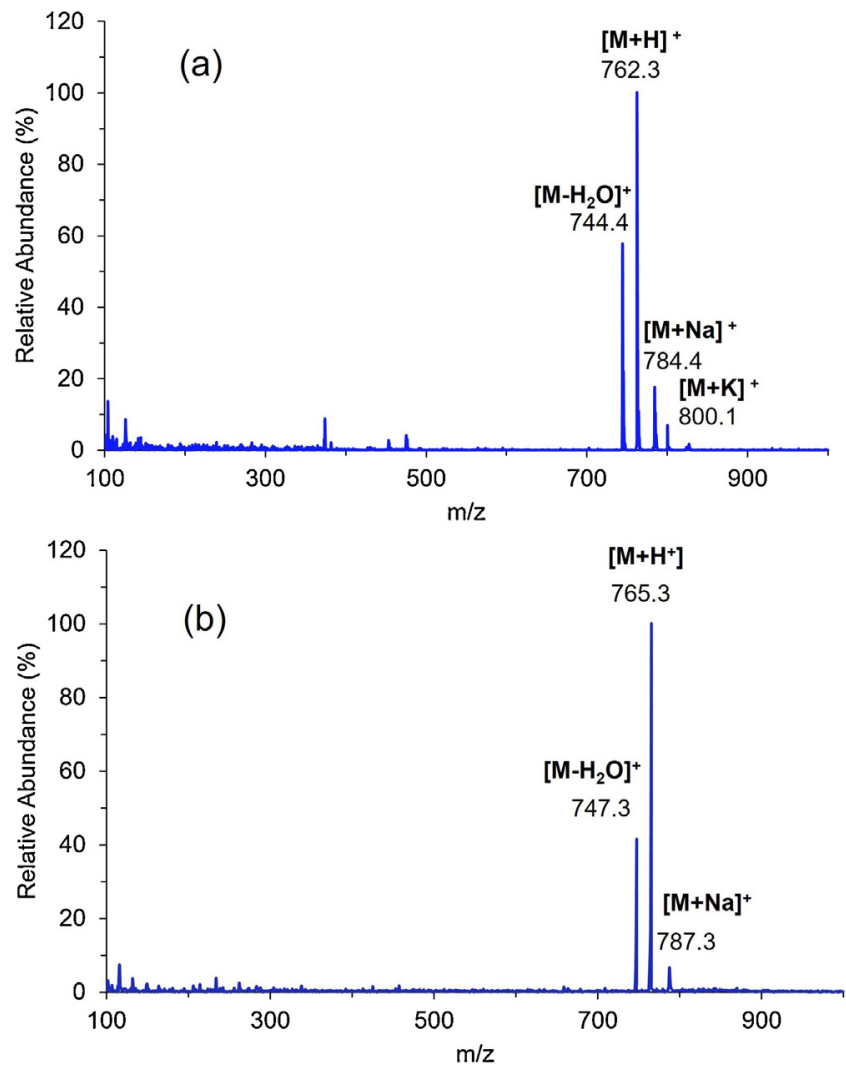

Fig. 2. Scan mass spectra of trabectedin (a) and $d_{3}$-trabectedin (b).

reactivity of the carbinolamine moiety in position C-21, which may be susceptible to nucleophilic substitution. Since the source of cyanide was identified as an impurity of acetonitrile, for all successive experiments as well as for mobile phase preparation only distilled acetonitrile was used.

Product ion scans of trabectedin and its $\mathrm{d}_{3}$-derivative are shown, along with a proposed fragmentation pattern, in Fig. 3a,b. Both scans have a representative intense ion fragment at $\mathrm{m} / \mathrm{z} 234$ that was selected to build the quantifier MRM transitions. The less abundant ion fragments with $\mathrm{m} / \mathrm{z} 206,557$ (for trabectedin) and 206, 560 (for $\mathrm{d}_{3}$-trabectedin) were instead chosen to build the qualifier MRM transitions. Collision energy and fragmentor voltage were optimized for all MRM transitions to obtain the highest MS signals.

\subsection{Liquid chromatography}

To develop the current method, we coupled an HILIC separation step to MS. In the presence of a high concentration of organic solvent, trabectedin showed good retention on the BEH Amide column, likely due to interactions of its hydrogen bond donors and acceptors with the polar stationary phase. Its column elution, occurring at about $70 \%$ acetonitrile, favored droplet desolvation and ESI ion formation. As a result, the MS signal improved as did the sensitivity of the method, in agreement with previous HILIC investigations [14-16]. Trabectedin was eluted selectively at 2.7 min during a total chromatographic run of $9 \mathrm{~min}$. The overall run time was comparable to that of existing analytical methods for trabectedin [9-11]. However HILIC offered the advantage to simplify sample preparation because the plasma extract was directly injected into the LC/MS system. This approach avoided sample dilution and time-consuming concentration steps, making the method straightforward and ideal for large-scale analyses.
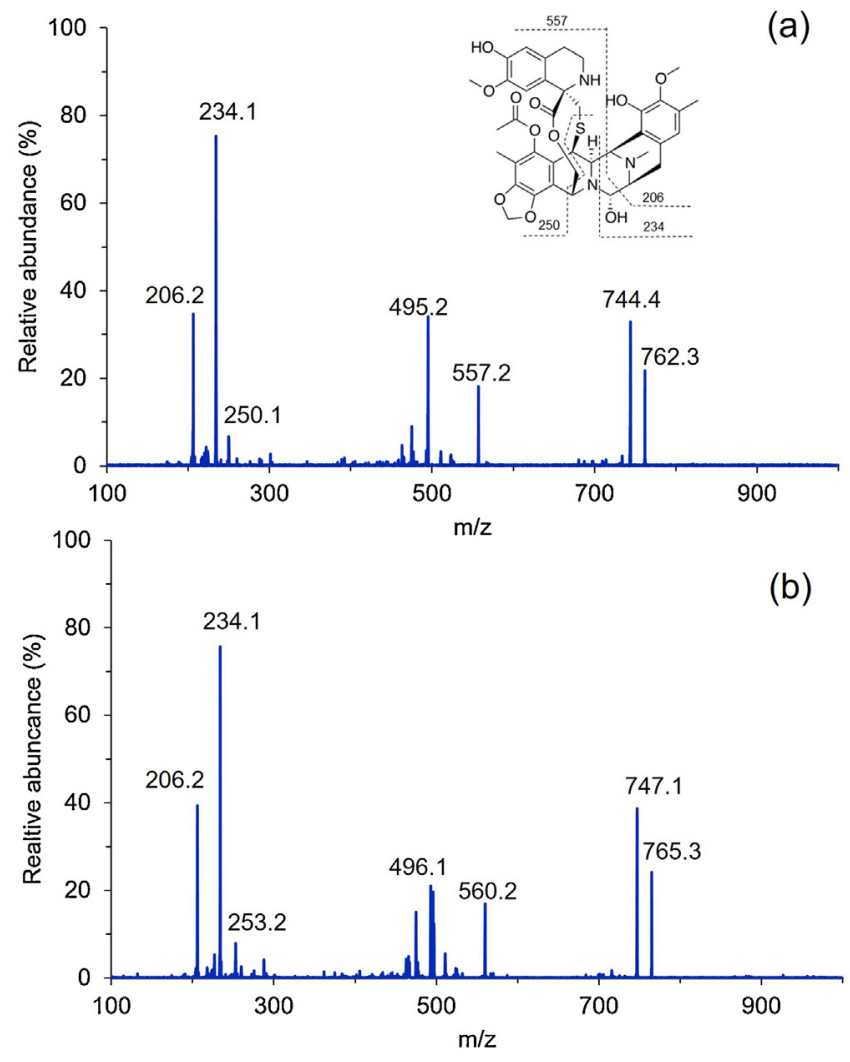

Fig. 3. Product ion mass spectra of trabectedin (a) and $d_{3}$-trabectedin (b) obtained at a collision energy of $30 \mathrm{~V}$.

\subsection{Method validation}

\subsubsection{Linearity and $L L O Q$}

Calibration curves in the range of $0.01-2.5 \mathrm{ng} / \mathrm{mL}$ (interpolated with a $1 / \mathrm{x}$ weighting factor) showed a correlation coefficient $\geq 0.9902$, indicating good linearity of the method. Back-calculated concentrations, evaluated over three independent runs, gave a RE ranging from $-13.31 \%$ to $10.68 \%$, while the RSD ranged from 0.04 $\%$ to $13.83 \%$. These results indicate good accuracy and precision.

The LLOQ was assigned to the lowest calibrator concentration with both RE and RSD $\leq 20 \%$. Under the current experimental conditions, the method maintained this level of accuracy and precision at $0.01 \mathrm{ng} / \mathrm{mL}$ trabectedin $(\mathrm{RE} \leq 7.80 \%$; RSD $\leq 13.83 \%)$. MRM chromatograms of a plasma blank and a plasma sample with trabectedin at the LLOQ are shown in Fig. 4a,b.

\subsubsection{Intra- and inter-day accuracy and precision}

The intra-day accuracy expressed as RE was in the range of -8.52 \% to $1.19 \%$ for the QC samples, while the precision expressed as RSD ranged from $3.95 \%$ to $12.35 \%$ (Table 2 ). The inter-day accuracy and precision for the QC samples, investigated over three days, ranged from $-6.78 \%$ to $-1.92 \%$ and from $6.57 \%$ to $10.74 \%$, respectively. These analyses fulfill the validation criteria.

\subsubsection{Recovery and matrix effect}

Several solvent extraction trials were carried out to maximize the overall recovery of trabectedin from the plasma matrix. Acetonitrile was the best solvent, especially when it contained $1 \%$ formic acid, giving a mean overall recovery of $54.4 \%(\mathrm{SD}=3.8 \%)$ (Fig. S2). The matrix effect was assayed by comparing the trabectedin MS signals between protein-free plasma samples with the drug at QC concentrations and neat solutions of drug [13]. The presence of matrix reduced the trabectedin MS signal by a mean of 

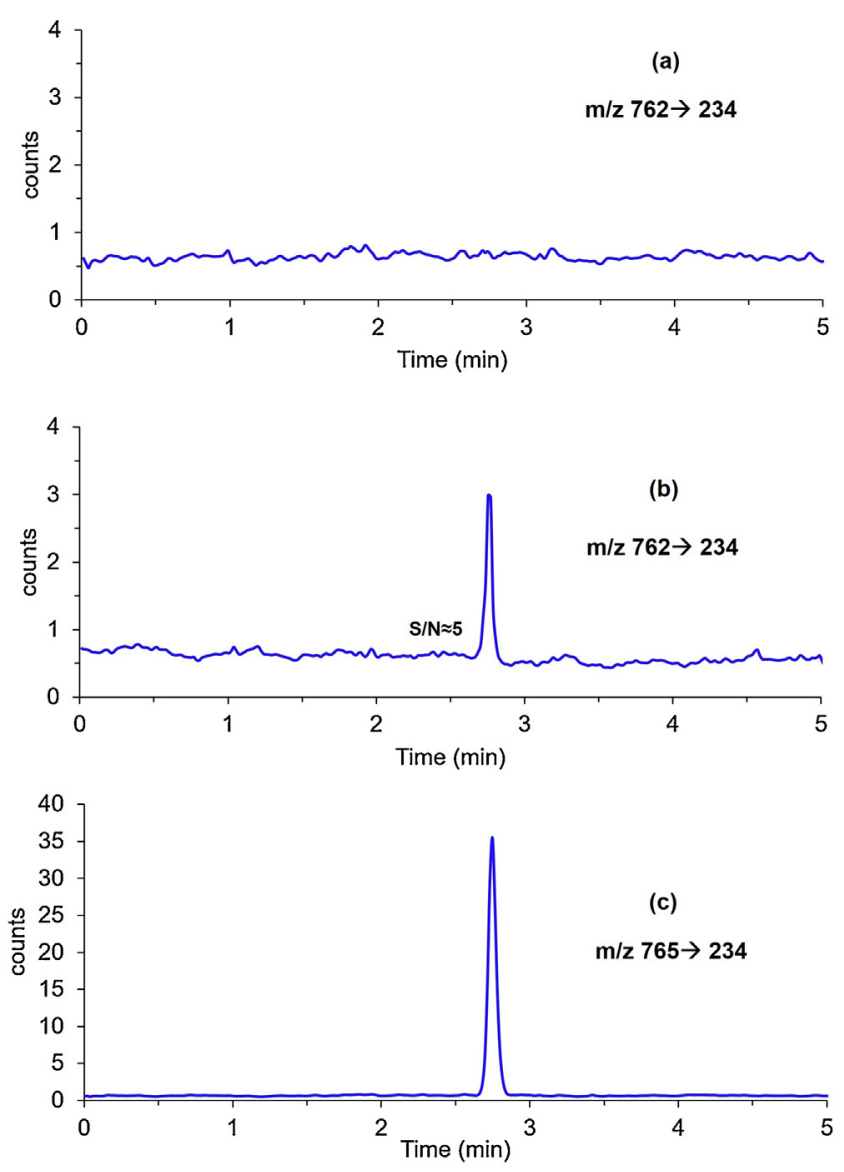

Fig. 4. Multiple reaction monitoring (MRM) chromatograms: (a) plasma blank; (b) plasma with trabectedin added at the LLOQ $(0.01 \mathrm{ng} / \mathrm{mL})$; and (c) plasma supplemented with $\mathrm{d}_{3}$-trabectedin (internal standard).

Table 2

Intra- and inter-day precision and accuracy for trabectedin in plasma.

\begin{tabular}{|c|c|c|c|c|}
\hline \multirow{2}{*}{ Sample concentration } & \multicolumn{3}{|l|}{ Intraday } & \multirow{2}{*}{$\begin{array}{l}\text { Interday } \\
\text { Days } 1-3 \\
(\mathrm{n}=24)\end{array}$} \\
\hline & $\begin{array}{l}\text { Day } 1 \\
(n=12)\end{array}$ & $\begin{array}{l}\text { Day } 2 \\
(n=6)\end{array}$ & $\begin{array}{l}\text { Day } 3 \\
(n=6)\end{array}$ & \\
\hline \multicolumn{5}{|l|}{ LLOQ, $0.01 \mathrm{ng} / \mathrm{mL}$} \\
\hline RSD (\%) & 13.83 & 9.30 & 11.22 & 12.49 \\
\hline $\mathrm{RE}(\%)$ & -0.20 & -7.16 & 7.80 & 0.72 \\
\hline \multicolumn{5}{|l|}{$\mathrm{QC}-\mathrm{L}, 0.04 \mathrm{ng} / \mathrm{mL}$} \\
\hline RSD (\%) & 12.35 & 3.95 & 11.66 & 10.74 \\
\hline $\mathrm{RE}(\%)$ & -3.21 & -6.24 & 1.19 & -2.87 \\
\hline \multicolumn{5}{|l|}{ QC-M, $0.16 \mathrm{ng} / \mathrm{mL}$} \\
\hline RSD (\%) & 6.26 & 7.97 & 6.76 & 6.57 \\
\hline $\mathrm{RE}(\%)$ & -1.50 & -1.37 & -3.32 & -1.92 \\
\hline \multicolumn{5}{|l|}{$\mathrm{QC}-\mathrm{H}, 0.80 \mathrm{ng} / \mathrm{mL}$} \\
\hline RSD (\%) & 4.75 & 6.30 & 10.61 & 7.00 \\
\hline $\mathrm{RE}(\%)$ & -7.75 & -3.10 & -8.52 & -6.78 \\
\hline
\end{tabular}

$R S D$, relative standard deviation; $R E$, relative error.

$24.5 \%(S D=5.1 \%)$, indicating a suppressive effect. Inclusion of $d_{3}-$ trabectedin, as an internal standard, kept this substantial matrix effect under control, highlighting its mandatory use for the quantification of trabectedin in plasma.

\subsubsection{Selectivity}

Analysis of six different plasma samples alone (double blanks) and spiked with trabectedin at the LLOQ revealed the absence of interfering peaks close to the trabectedin retention time in the MRM chromatograms of the double blanks. The RE in these analy-
Table 3

Stability of trabectedin in different experimental conditions and concentrations.

\begin{tabular}{llc}
\hline Conditions & $\begin{array}{l}\text { Nominal } \\
\text { concentration } \\
(\mathrm{ng} / \mathrm{mL})\end{array}$ & $\mathrm{RE}(\%)$ \\
\hline Short-term stability: $4^{\circ} \mathrm{C}, 4 \mathrm{~h}$ & 0.04 & 10.72 \\
& 0.16 & -0.44 \\
Short-term stability: room temperature, $4 \mathrm{~h}$ & 0.80 & -4.47 \\
& 0.04 & 10.39 \\
Plasma extract stability: $4{ }^{\circ} \mathrm{C}, 24 \mathrm{~h}$ & 0.16 & 1.59 \\
& 0.80 & 9.60 \\
& 0.04 & 2.16 \\
& 0.16 & 8.43
\end{tabular}

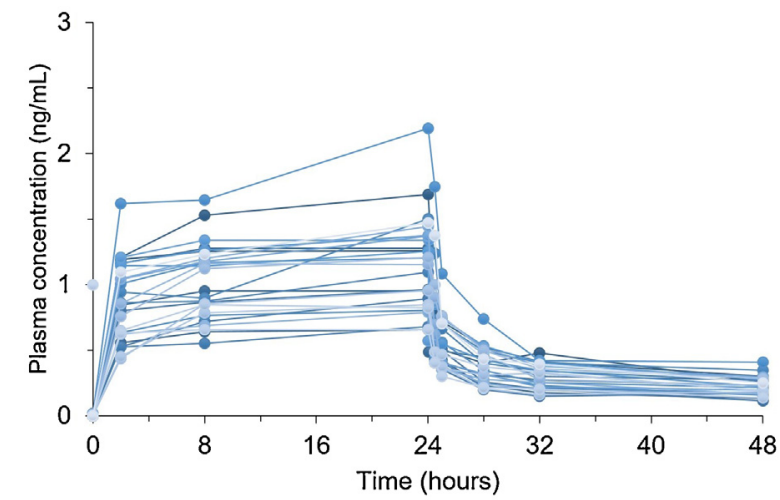

Fig. 5. Plasma concentration-versus-time profile of trabectedin in soft tissue sarcoma patients $(\mathrm{n}=26)$ determined using the new HILIC-MS/MS method. Trabectedin was administered at the dose of $1.5 \mathrm{mg} / \mathrm{m}^{2}$ as a $24 \mathrm{~h}$ intravenous infusion.

ses ranged from $-10.59 \%$ to $6.02 \%$, demonstrating good selectivity of the method.

\subsubsection{Stability}

QC samples were found to be stable at both $4{ }^{\circ} \mathrm{C}$ and room temperature for $4 \mathrm{~h}$, indicating that the sample preparation procedure can also be performed at room temperature within $4 \mathrm{~h}$ of collection (Table 3). Moreover, the freeze-thaw cycles did not noticeably affect the stability of trabectedin, and the plasma extracts kept at $4{ }^{\circ} \mathrm{C}$ in the auto-sampler showed good stability up to $24 \mathrm{~h}$ with an accuracy of the QC concentrations less than $8.63 \%$. Lastly, the long-term stability of QCs at $-30^{\circ} \mathrm{C}$ over 3 months was characterized by a slow degradation that did not exceed $15 \%$. Overall, these results are in agreement with those reported in previous studies [9].

\subsection{Clinical suitability}

The developed method was tested in a clinical setting by monitoring the trabectedin pharmacokinetic profile in plasma from 26 STS patients treated with a $24 \mathrm{~h}$ continuous intravenous infusion of trabectedin at a dose of $1.5 \mathrm{mg} / \mathrm{m}^{2}$. As soon as the infusion had started, the level of trabectedin in blood rose quickly (Fig. 5). The level reached a steady state at about $8 \mathrm{~h}$ and stayed almost constant up to $24 \mathrm{~h}$. The concentration promptly decreased after completion of the infusion, and the drug was quickly eliminated by bi-exponential kinetics.

Pharmacokinetic analyses (Table 4) revealed a median drug exposition, expressed as $\mathrm{AUC}_{0-48 \mathrm{~h}}$, of $33.28 \mu \mathrm{g} \cdot \mathrm{h} \cdot \mathrm{L}^{-1}$ (range, 19.0-55.5) and a median $C_{\max }$ of $1.8 \mu \mathrm{g} / \mathrm{L}$ (range, 0.7-2.2). Median MRT was $18.17 \mathrm{~h}$ (range, 13.9-20.4), in agreement with previously reported data $[17,18]$. These data document the suitability and utility of this bioanalytical method for clinical use. 


\section{Conclusions}

A novel LC-MS/MS method for trabectedin quantification based on HILIC has been developed and validated. The method is highly selective, linear, precise and accurate. Its sensitivity, straightforward pre-analytical process and short analytical cycle time make this a useful bioanalytical method for high-throughput pharmacokinetic monitoring in trabectedin clinical trials.

\section{Funding} funds.

This research was supported by Ministero della Sanità $5 \times 1000$

\section{CRediT authorship contribution statement}

Emanuela Di Gregorio: Investigation, Validation, Formal analysis, Writing - original draft, Writing - review \& editing. Gianmaria Miolo: Resources, Writing - review \& editing. Agostino Steffan: Project administration, Funding acquisition, Writing - review \& editing. Giuseppe Corona: Conceptualization, Supervision, Funding acquisition, Formal analysis, Writing - original draft, Writing review \& editing.

\section{Declaration of Competing Interest}

The authors declare that they have no known competing financial interests or personal relationships that could have appeared to influence the work reported in this paper.

\section{Acknowledgments}

This study was supported by Ministero della Sanità 5x1000 funds. Valerie Matarese provided scientific editing.

\section{Appendix A. Supplementary data}

Supplementary material related to this article can be found, in the online version, at doi:https://doi.org/10.1016/j.jpba.2020. 113261.

\section{References}

[1] Y. Pommier, G. Kohlhagen, C. Bailly, M. Waring, A. Mazumder, K.W. Kohn, DNA sequence- and structure-selective alkylation of guanine N2 in the DNA minor groove by ecteinascidin 743 , a potent antitumor compound from the Caribbean tunicate Ecteinascidia turbinata, Biochemistry 35 (1996) 13303-13309, http://dx.doi.org/10.1021/bi960306b.

[2] M. D'Incalci, C.M. Galmarini, A review of trabectedin (ET-743): a unique mechanism of action, Mol. Cancer Ther. 9 (2010) 2157-2163, http://dx.doi org/10.1158/1535-7163.MCT-10-0263.

[3] G. Germano, R. Frapolli, C. Belgiovine, A. Anselmo, S. Pesce, M. Liguori, E. Erba, S. Uboldi, M. Zucchetti, F. Pasqualini, M. Nebuloni, N. van Rooijen, R. Mortarini, L. Beltrame, S. Marchini, I. Fuso Nerini, R. Sanfilippo, P.G. Casali, S. Pilotti, C.M. Galmarini, A. Anichini, A. Mantovani, M. D’Incalci, P. Allavena, Role of macrophage targeting in the antitumor activity of trabectedin, Cancer Cell 23 (2013) 249-262, http://dx.doi.org/10.1016/j.ccr.2013.01.008.

[4] Yondelis | European Medicines Agency, (n.d.). https://www.ema.europa.eu/ en/medicines/human/EPAR/yondelis (accessed November 25, 2019).

[5] N. Colombo, E. Zaccarelli, A. Baldoni, S. Frezzini, G. Scambia, E. Palluzzi, G. Tognon, A.A. Lissoni, D. Rubino, A. Ferrero, G. Farina, E. Negri, A. Pesenti Gritti,
F. Galli, E. Biagioli, E. Rulli, D. Poli, C. Gerardi, V. Torri, R. Fossati, M. D'Incalci, Multicenter, randomised, open-label, non-comparative phase 2 trial on the efficacy and safety of the combination of bevacizumab and trabectedin with or without carboplatin in women with partially platinum-sensitive recurrent ovarian cancer, Br. J. Cancer 121 (2019) 744-750, http://dx.doi.org/10.1038/ s41416-019-0584-5.

[6] R. Frapolli, E. Bello, M. Ponzo, I. Craparotta, L. Mannarino, S. Ballabio, S. Marchini, L. Carrassa, P. Ubezio, L. Porcu, S. Brich, R. Sanfilippo, P.G. Casali, A. Gronchi, S. Pilotti, M. D'Incalci, Combination of PPAR $\gamma$ agonist pioglitazone and trabectedin induce adipocyte differentiation to overcome trabectedin resistance in myxoid liposarcomas, Clin. Cancer Res. (2019), http://dx.doi.org/ 10.1158/1078-0432.CCR-19-0976.

[7] A. Gronchi, N. Hindi, J. Cruz, J.-Y. Blay, A. Lopez-Pousa, A. Italiano, R. Alvarez, A. Gutierrez, I. Rincón, C. Sangalli, J.L. Pérez Aguiar, J. Romero, C. Morosi, M.P. Sunyach, R. Sanfilippo, C. Romagosa, D. Ranchere-Vince, A.P. Dei Tos, P.G. Casali, J. Martin-Broto, Trabectedin and RAdiotherapy in Soft Tissue Sarcoma (TRASTS): Results of a Phase I Study in Myxoid Liposarcoma from Spanish (GEIS), Italian (ISG), French (FSG) Sarcoma Groups, EClinicalMedicine 9 (2019) 35-43, http://dx.doi.org/10.1016/j.eclinm.2019.03.007.

[8] G. Grignani, L. D’Ambrosio, Y. Pignochino, E. Palmerini, M. Zucchetti, P. Boccone, S. Aliberti, S. Stacchiotti, R. Bertulli, R. Piana, S. Miano, F. Tolomeo, G. Chiabotto, D. Sangiolo, A. Pisacane, A.P. Dei Tos, L. Novara, A. Bartolini, E. Marchesi, M. D'Incalci, A. Bardelli, P. Picci, S. Ferrari, M. Aglietta, Trabectedin and olaparib in patients with advanced and non-resectable bone and soft-tissue sarcomas (TOMAS): an open-label, phase 1b study from the Italian Sarcoma Group, Lancet Oncol. 19 (2018) 1360-1371, http://dx.doi.org/10. 1016/S1470-2045(18)30438-8.

[9] H. Rosing, M.J.X. Hillebrand, J.M. Jimeno, A. Go, R.E.C. Henrar, J.B. Vermorken, E. Cvitkovic, A. Bult, J.H. Beijnen, Quantitative determination of Ecteinascidin 743 in human plasma by miniaturized high-performance liquid chromatography coupled with electrospray ionization tandem mass spectrometry, J. Mass Spectrom. 7 (1998).

[10] E. Stokvis, H. Rosing, L. López-Lázaro, J.H. Beijnen, Simple and sensitive liquid chromatographic quantitative analysis of the novel marine anticancer drug Yondelis $^{T M}$ (ET-743, trabectedin) in human plasma using column switching and tandem mass spectrometric detection, J. Mass Spectrom. 39 (2004) 431-436, http://dx.doi.org/10.1002/jms.608.

[11] M. Zangarini, L. Ceriani, F. Sala, E. Marangon, R. Bagnati, M. D’Incalci, F. Grosso M. Zucchetti, Quantification of trabectedin in human plasma: validation of a high-performance liquid chromatography-mass spectrometry method and its application in a clinical pharmacokinetic study, J. Pharm. Biomed. Anal. 95 (2014) 107-112, http://dx.doi.org/10.1016/j.jpba.2014.02.018.

[12] C. for D.E. and Research, Bioanalytical Method Validation Guidance for Industry, U.S. Food and Drug Administration, 2019 (Accessed November 25, 2019) http://www.fda.gov/regulatory-information/search-fda-guidancedocuments/bioanalytical-method-validation-guidance-industry.

[13] A. Van Eeckhaut, K. Lanckmans, S. Sarre, I. Smolders, Y. Michotte, Validation of bioanalytical LC-MS/MS assays: evaluation of matrix effects, J. Chromatogr. B 877 (2009) 2198-2207, http://dx.doi.org/10.1016/j.jchromb.2009.01.003.

[14] A. Abdulla, S. Bahmany, R.A. Wijma, B.C.H. van der Nagel, B.C.P. Koch, Simultaneous determination of nine $\beta$-lactam antibiotics in human plasma by an ultrafast hydrophilic-interaction chromatography-tandem mass spectrometry, J. Chromatogr. B 1060 (2017) 138-143, http://dx.doi.org/10. 1016/j.jchromb.2017.06.014.

[15] P.A. Lobue, M. Jora, B. Addepalli, P.A. Limbach, Oligonucleotide analysis by hydrophilic interaction liquid chromatography-mass spectrometry in the absence of ion-pair reagents, J. Chromatogr. A 1595 (2019) 39-48, http://dx doi.org/10.1016/j.chroma.2019.02.016.

[16] U.L. Kathriarachchi, S.S. Vidhate, N. Al-Tannak, A.H. Thomson, M.J.J. da Silva Neto, D.G. Watson, Development of a LC-MS method for simultaneous determination of amoxicillin and metronidazole in human serum using hydrophilic interaction chromatography (HILIC), J. Chromatogr. B 1089 (2018) 78-83, http://dx.doi.org/10.1016/j.jchromb.2018.05.012.

[17] J.J. Perez-Ruixo, P. Zannikos, S. Hirankarn, K. Stuyckens, E.A. Ludwig, A. Soto-Matos, L. Lopez-Lazaro, J.S. Owen, Population pharmacokinetic meta-analysis of trabectedin (ET-743, yondelis ${ }^{\circledR}$ ) in cancer patients, Clin. Pharmacokinet. 46 (2007) 867-884, http://dx.doi.org/10.2165/00003088200746100-00005.

[18] I. Poggesi, B. Valenzuela, D. Ouellet, M. Gonzalez, V. Hillewaert, S. Baruchel, E. Fox, J.J. Perez-Ruixo, Population pharmacokinetics of trabectedin in adolescent patients with cancer, Cancer Chemother. Pharmacol. 84 (2019) 707-717, http://dx.doi.org/10.1007/s00280-019-03899-y. 